\title{
A DIVINA COMÉDIA DE UM RAPAZ LATINO-AMERICANO: A INFLUÊNCIA DA LITERATURA NA OBRA DE BELCHIOR
}

\author{
THE “DIVINECOMEDY”OF A LATIN AMERICAN BOY: THE \\ INFLUENCEOFLITERATUREONBELCHIOR'SWORK
}

Leandro Martan Bezerra Santos ${ }^{1}$

\begin{abstract}
Resumo: O presente artigo visa apresentar a influência da literatura e a utilização de recursos de intertextualidades na obra do músico cearense Belchior. A partir da análise das letras das cerca de cento e vinte composições gravadas pelo artista, aliada à uma breve contextualização de sua trajetória profissional, será possível identificar e promover uma reflexão sobre os pontos de convergência entre música e literatura na obra deste consagrado cantor da Música Popular Brasileira.
\end{abstract}

Abstract: This paper aims to show the influence of literature and the use of intertextual resources in the work of the Brazilian musician Belchior. Using the lyrics of all one hundred and twenty compositions recorded by the artist, combined with a brief contextualization of his professional career, it will be possible to identify and promote a reflection on the points of convergence between music and literature in the work of this renowned singer of the musical genre well known as the "Brazilian Popular Music".

Palavras-chave: Antonio Carlos Belchior; História da cultura no Brasil; História social brasileira; Música popular brasileira; Música e literatura.

Keywords: Antonio Carlos Belchior; Brazilian music; Brazilian social history; History of culture in Brazil; Music and literature.

\section{Introdução}

Antonio Carlos Belchior foi um dos mais conhecidos, talentosos e icônicos compositores e intérpretes da Música Popular Brasileira. Nascido no ano de 1946, na cidade de Sobral, Ceará, construiu uma trajetória artística singular, cujas peculiaridades se estendiam do abandono do curso de Medicina na Universidade Federal do Ceará, a fim de se dedicar às crescentes participações em festivais universitários de música, ao repentino sumiço dos palcos e dos holofotes na fase final de sua carreira.

O presente artigo debruça-se especificamente sobre as confluências entre literatura e música na formação das letras compostas por Belchior, que valorizou, como poucos compositores brasileiros foram capazes de fazer, os gêneros literários como influências indispensáveis para a sua 1 Mestrando em Arqueologia na Universidade de São Paulo (MAE/USP), onde é bolsista CAPES e atua como Pesquisador do Laboratório Interfaces entre Museologias - InterMuseologias, sob a orientação da Profa. Dra. Marília Xavier Cury. É Bacharel em Ciências Sociais pela Fundação Getulio Vargas (CPDOC/FGV), com formação complementar em Relações Internacionais no Mundo Contemporâneo. Foi bolsista de Iniciação Científica por dois anos, tendo integrando como estudante os seguintes grupos de pesquisa: Laboratório de Pensamento Social - LAPES (FGV); Cátedra Jean Monnet (FGV) e Estudos Avançados para a Sustentabilidade - EAS (UFRN). Já apresentou trabalhos, publicou artigos, fez cursos e participou de eventos nos âmbitos nacional e internacional. Tem experiência profissional no Museu Câmara Cascudo e no IBGE, além de ter sido discente das graduações em Direito da Universidade Federal do Rio de Janeiro (FND/UFRJ) e de Turismo da Universidade Federal do Rio Grande do Norte (UFRN). Possui interesse nas seguintes áreas: História Cultural do Brasil; Museologia Crítica; Arqueologia Pública; Arquivos de Imprensa; Humanidades Digitais; História da Política Externa Brasileira; Política Internacional e Relações Internacionais. 
obra, estabelecendo um enorme e complexo fluxo de intertextualidades em sua produção. A análise detalhada das cerca de cento e vinte composições gravadas por Belchior permitiu a identificação de inúmeras produções literárias que foram referenciadas e se fizeram presentes na obra do músico cearense, com o rol de fontes também sendo composto por trabalhos acadêmicos sobre a temática e o próprio Belchior.

Ainda antes do início de sua carreira artística, Belchior deixou a cidade de Sobral para buscar cumprir com sua vocação religiosa, indo morar num convento de freis capuchinhos na pequena cidade de Guaramiranga, região serrana do Ceará. A sólida formação intelectualoriunda dos anos passados junto aos capuchinhos possibilita uma influência fundamental sobre as composições tão complexas e ricas em referências literárias, culturais e sociológicas presentes em suas letras, que se refletiam diretamente na qualidade e no direcionamento temático de suas composições.

A respeito dessa característica da obra do cearense, Gislene Silva conclui que:

No aspecto estético, Belchior constrói sua obra dentro de um estilo original, tanto do ponto de vista temático, quanto da linguagem. São letras impregnadas de poesia, textos que, se retirados do ambiente musical em que foram produzidos, permanecem como versos de evidente qualidade literária. Não são apenas documentos de um momento histórico efervescente, mas a configuração estética de uma poesia que, imbricada nas letras do cancioneiro popular urbano da década de 1970 e 1980, adquiriu tamanha força lírica a ponto de revelar uma vida independente do suporte melódico e sustentar-se seguramente apenas pela leitura. Ademais, sua obra está presente na literatura brasileira, como também a literatura brasileira está presente, por meio da intertextualidade, em sua elaboração poética. (...) Suas criações apontam um engajamento dentro da série social e literária, renunciando, na medida do possível, às exigências e imposições do mercado fonográfico e da indústria cultural (SILVA, 2006, pp. 104 - 105).

Após as experiências com a religião e a universidade, o cantor deixou o Nordeste do país para buscar ampliar a projeção de sua carreira. O período inicial da vida no Rio de Janeiro e em São Paulo, com todas as dificuldades e experiências adjacentes à vida na cidade grande, se tornou lugar comum na temática de suas obras, quando Belchior pôde acompanhar de perto os processos provenientes das transformações urbanas e sociais das grandes cidades do Sudeste brasileiro, com especial ênfase na situação dos imigrantes nordestinos que ali chegavam em imensa quantidade. Foi nessa mesma época, porém, que o músico lançou seus álbuns de maior sucesso junto ao público e à crítica, sendo eles Alucinação - seu disco mais vendido e datado de 1976 - e Coração Selvagem, do ano de 1977. 


\section{Diálogos com a literatura e literatos}

Embora não fosse o tema principal das canções de Belchior, a literatura se manifestava de maneira constante nessas composições, especialmenteatravés do uso do recurso da intertextualidade, isto é, a ocorrência de um diálogo entre dois ou mais textos, independentemente do grau da relação entre eles. É possível identificar também referências a grandes nomes internacionais dos campos da filosofia, poesia, artes plásticas e visuais, cinema, teatro, assim como figuras públicas em geral, nos revelando uma aguda face intelectual do artista, que estudava, acompanhava e admirava expoentes de todas as áreas acima citadas, com frequência conciliando tal interesse com encaixes que formavam um todo coerente, coeso e harmônico na estrutura de elaboração de suas canções.

Como exemplo dessa ampla dinâmica de referências, em "Retórica sentimental", do disco Era uma vez um homem e o seu tempo, Belchior faz menção direta a Gonçalves Dias e sua "Canção do exílio", além decitar a personagem Ceci do romance "O Guarani”, do também cearense José de Alencar,e mencionar o poema "Buriti Perdido", de Afonso Arinos.

A menção a poemas e poetas é um dos caminhos de diálogos intelectuais mais utilizados por Belchior: em "Pequeno mapa do tempo", do disco Coração Selvagem, faz referência ao poema "Congresso Internacional do Medo", de Carlos Drummond de Andrade. Opoema é ainda mencionado nesse mesmo álbum, na canção-protesto "Populus". Já em "Aguapé”, fruto de parceria com Raimundo Fagner em Objeto Direto, homenageia o poeta baiano Castro Alves ao utilizar - com pequenas alterações - trecho do poema "A Cruz da Espada" na epígrafe da canção. O poeta espanhol Federico García Lorca é rememorado nos trechos "botas de sangue nas roupas de Lorca" - em "Conheço o meu lugar", de Era uma vez um homem e seu tempo - e "poeta tombado na guerra civil", em "E que tudo mais vá para o céu”, de Paraíso. Conforme apontamento feito por Josely Carlos (2007, pp. 139 - 140), o português Fernando Pessoa também entra na seleção em "Todo sujo de batom" e "Balada do amor perverso", assim como ocorre com John Donne, autor do poema "Elegia", mencionado no seguinte trecho de "Em resposta à carta de fâ": "Pra terminar, meu livro de cabeceira, para ler com todo o corpo / É aquele de que fala a Elegia de Donne”.

Sua obra também nos indica associação com aspectos da poesia concretista, como declara em "Como se fosse pecado", de Coração Selvagem: "Preciso, precisamos, da verdade, nua e crua / E não vou remendar vosso soneto / Batuco um canto concreto pra balançar o coreto".

Recursos concretistas na obra de Belchior são analisados nas canções “Mote e Glosa”(CARLOS, 2007, p. 187) e "Bebelo" (COSTA, 2012). Dessa forma, procederemos aqui com a representação da composição "Máquina", exposta a seguir conforme encarte do disco de estreia do cantor, referenciado como Mote e Glosa: 
mê

e $\quad \mathrm{m}$

e $\quad \mathrm{m} \quad \mathrm{e} \quad \mathrm{a} \quad \mathrm{m} \quad \mathrm{a}$

$\begin{array}{lllllll}\mathrm{q} & \mathrm{u} & \mathrm{i} & \mathrm{q} & \mathrm{u} & \mathrm{i}\end{array}$

$\begin{array}{llllll}\mathrm{e} & \mathrm{n} & \mathrm{e} & \mathrm{a} & \mathrm{n} & \mathrm{a}\end{array}$

$\begin{array}{llllll}\mathrm{e} & \mathrm{m} & \mathrm{a} & \mathrm{a} & \mathrm{m} & \mathrm{a}\end{array}$

$\begin{array}{lllllll}\mathrm{q} & \mathrm{u} & \mathrm{i} & \mathrm{q} & \mathrm{u} & \mathrm{i}\end{array}$

$\begin{array}{llllll}\text { e } & n & \text { e } & \text { a } & \text { n } & \text { a }\end{array}$

e $\quad \mathrm{m} \quad \mathrm{e} \quad \mathrm{a} \quad \mathrm{m} \quad \mathrm{a}$

$\begin{array}{lllllll}\mathrm{q} & \mathrm{u} & \mathrm{i} & \mathrm{q} & \mathrm{u} & \mathrm{i}\end{array}$

e $n \quad$ e $\quad$ a $\quad n \quad a$

e $\quad \mathrm{m} \quad \mathrm{e} \quad \mathrm{a} \quad \mathrm{m} \quad \mathrm{a}$

q

u $\quad \mathrm{i} \quad \mathrm{q} \quad \mathrm{u}$

a

n a

n a

$\mathrm{n} \quad \mathrm{a}$

n a

n a

n a

máquina máquina

máquina máquina

máquina máquina

máquina máquina

máquina máquina

máquina máquina

máquina máquina

máquina máquina

m a m a

máquina máquina

máquina máquina

máquina máquina

máquina máquina

máquina máquina

na na na na 
São exemplos da abrangência de influências literárias as menções feitas - apenas na faixa "Os derradeiros moicanos", componente do álbum Melodrama, lançado em 1987 - a Jean-Jacques Rousseau, Jacques Brel, Pablo Picasso, Marcel Duchamp, François-René Chateaubriand, Henri Salvador, Arthur Rimbaud - também lembrado na letra de "Os Profissionais", do disco Elogio da Loucura, e Charles Baudelaire - estes dois últimos através de uma brincadeira com os nomes, formando "Rimbaudelaire", como é possível observar no seguinte excerto da canção:

\author{
Nós somos uns pobres diabos sul-americanos, ô, ô, ô, ô \\ Os derradeiros moicanos, ô, ô, ô \\ Perís, cecis, guaranis - um glamour de índios de Chateubriand (...) \\ Lá em São Luís \\ Cristão infeliz, o bom selvagem aprende francês \\ Pra ler e escrever o poema do Brasil no original, pela primeira vez \\ E nesses brasis - um paris tropical - Henri salvador de Martinique (...) \\ Alavantú, nossa gangue, a quadrilha do sangue danse lá enarrière \\ Que sonhamos, nos campos, Duchamp, Picasso e Rimbaudelaire (...) \\ Brilhe o belga Jacques Brel, já que bel nisso não é de brilhar
}

O mesmo jogo de palavras é feito no título de uma de suas mais emblemáticas músicas, "Divina comédia humana", de Todos os sentidos, onde Belchior une os títulos das obras "Divina comédia", monumental poema escrito pelo italiano Dante Alighieri - obra que Belchior almejava adaptar para uma linguagem popular -, e "A comédia humana", título escolhido pelo francês Honoré de Balzac para nomear toda a sua obra. Nessa mesma canção há, ainda, um trecho no qual Belchior faz uso intertextual do início do poema "Ouvir estrelas”, do poeta parnasiano brasileiro Olavo Bilac.

Eu quero gozar no seu céu, pode ser no seu inferno

Viver a divina comédia humana onde nada é eterno

Ora, direis ouvir estrelas, certo perdeste o senso

Eu vos direi, no entanto:

Revista Crioula - $\mathbf{n}^{\circ} \mathbf{2 6}$ - Relações entre literatura e música na produção de língua portuguesa

$2^{\circ}$ Semestre 2020 
Há nova referência à obra-prima de Dante em "Baihuno", de disco homônimo, em "Mais uma estação no inferno / Babilônia / Dante eterno!”. Já Duchamp volta a ser mencionado de maneira direta em "Madame', e indireta em "Do Mar, do céu, do campo", de Paraíso, quando Belchior invoca "Rose Selavy", o nome do alterego feminino do pintor e poeta francês.

Sobre o recurso de alusão amplamente empregado nas músicas de Belchior, os autores Antonia Oliveira, Francisco Leite e Maria Sousa (2017, p. 636) consideram que "mais do que qualquer outra forma de intertextualidade (...), a alusão é a forma que mais precisa acionar o conhecimento prévio de leitor, (...) ao supor que ele possa compreender nas entrelinhas o que o autor deseja sugerir-lhe sem expressar diretamente".

Ao longo de outras canções,há ainda a alusão direta a grandes obras da literatura mundial, como quando Belchior cita em "Clamor no Deserto", de Coração Selvagem, a obra 1984, de George Orwell, conversa com "O Corvo" de Edgar Allan Poe, nos versos finais de "Velha roupa colorida", de Alucinação,e emprega a frase em francês "balladedesdamesdutempsjadis", título de poema de François Villon, utilizada na canção "Balada de MadameFrigidaire",letra onde também ocorre menção à peça grega "Édipo Rei”, de Sófocles.

"Amor de perdição" -expressão originalmente título do romance do português Camilo Castelo Branco -,é lançada no álbum Elogio da Loucura, de 1988.A própria nomenclatura desse álbum é tomada emprestada por Belchior da obra homônima do holandês Erasmo de Roterdã. O mesmo ocorre na música "Lira dos 20 anos", uma das suas canções de maior sucessoe que também foi lançada em Elogio da Loucura, que emprega no título a menção direta à antologia poética que reuniu a obra de Álvares de Azevedo.

O escritor uruguaio Eduardo Galeano e seu clássico "As veias abertas da América Latina" são lembrados em diálogo traçado na letra de "Ploft", de Cenas do próximo capítulo, assim como o jornalista e escritor Euclides da Cunha e seu "sertanejo forte", ao qual é feita referência em "Notícia de terra civilizada", gravada em Baihuno. Também do disco Baihunovêm menções a Lord Byron e William Blake, como se vê letra de "Se você tivesse aparecido": "Se você tivesse aparecido em minha adolescência / Canção blake de inocência / Amor, quem não teria ido e vivido com Byron / O bardo da gangue do "le me perishyoung"'.Lord Byron volta a ser registrado no trabalho de Belchior, desta vez de maneira indireta, quando o músico lança em Melodrama a canção "Dandy".

A respeito da ligação entre o termo "dândi" e o trabalho literário de Byron, ao observar 
oethospresente nas composições de Belchior, nos esclarece JoselyCarlos que "O dandismo está relacionado à criação por Byron de um fascinante jovem sexy, de energia impetuosa e desafiadora (...) o dândi deve ser sublime. Como atitude filosófica, o dandismo constitui-se numa forma de rebeldia, com repertório próprio de valores" (2007, p. 129).

Um dos projetos paralelos de Belchior foi o disco Eldorado, gravado com a colaboração de músicos uruguaios, que consistia em versões na língua espanhola de algumas de suas canções mais consagradas, além de uma faixa inédita. O título dessa canção, "La vida es sueño", reproduz e homenageia a denominação de uma obra literária, neste caso uma das mais conhecidas peças de teatro escrita por Pedro Calderón de La Barca, um dos integrantes da lista de ícones espanhóis conhecidos por marcar o chamado "século de ouro" da produção cultural daquele país, situado entre os séculos XVI e XVII. Deve-se acrescentar à sua extensa relação com a literatura um álbum inteiro gravado com poemas de Carlos Drummond de Andrade musicados pelo próprio Belchior, intitulado As várias caras de Drummond.

Belchior nos narra em "Rock romance de um robô goliardo" - de Cenas do próximo capítulo - um cenário no qual um filho abandona sua casa e escola com o sonho de se tornar um artista de rock, enquanto é duramente repreendido por sua irritada mãe, no que pode ser interpretado como uma anedota sobre a desistência dos estudos para tentar a sorte como músico no Rio de Janeiro e em São Paulo, como exemplifica o trecho:

Ia pondo o pé na rua quando a minha velha saltou de lá muito cheia de si

Me chamando: "Playboy! Rebelde! Transviado!", como se fosse dona do mundo.

E foi logo dizendo:

"Pra você ver a vida como é: a gente cria um bicho desses

Educa, dá do bom e do melhor

Casa e comida, roupa lavada, amor, carinho, mesada

E esse aventureiro termina deixando a escola

Fugindo de casa, maldizendo a família

Querendo ser cantor de rock!”

A própria utilização do termo "goliardo" no título da canção, cunhado com o objetivo de associar Belchior aos poetas medievais com educação religiosa que integravam as universidades e 
escreviam em latim (RIBAS, 2014), denotava o convite feito pelo compositor para que seus ouvintes o entendessem como alguém oriundo das influências intelectuais e culturais das vidas universitária e eclesiástica. Bela e feliz analogia para alguém que sugere - em "Humano Hum, de Todos os Sentidos, "lavrar a palavra a pá".

Nessa mesma canção há, ainda, uma comunicação com o manifesto antropófago de Oswald de Andrade, ao escrever "eu sou um antropófago urbano/Um canibal delicado na selva da cidade/Mais dia, menos dia... eu como você”.

O "cantar novo" de Belchior, de jeito fácil e claro, intitula uma de suas mais conhecidas composições: "A palo seco". Há, nesse caso, uma referência direta ao poema de autoria do escritor e diplomata brasileiro João Cabral de Melo Neto, originalmente publicado no livro "Quaderna", em 1960. No poema A palo seco, Melo Neto fala sobre o estilo de canto que dá nome à canção e que depois viria a se associar à figura de Belchior, classificando-o como um jeito de cantar simples e extremo, sem guitarra elétrica ou outros tipos de acompanhamento, feito somente com a voz, anedoticamente tratada como uma lâmina.

\section{Intertextualidades e relação com as artes e as ciências humanas e sociais}

Na canção "Meu cordial brasileiro" - lançada em Era uma vez um homem e o seu tempo -, Belchior vai além e intitula a música em referência à ideia de "homem cordial" explorada pelo célebre sociólogo e historiador Sérgio Buarque de Holanda, estabelecendo diálogos com três ícones da constituição do pensamento social brasileiro: o sociólogo e ensaísta pernambucano Gilberto Freyre; o antropólogo mineiro Darcy Ribeiro; e, por fim, com o também antropólogo francês Claude Lévi-Strauss, cujo trabalho foi fortemente influenciado e direcionado ao período em que trabalhou e produziu estudos no Brasil.

Como nos mostra o exemplo a seguir, Belchior faz alusão ao chamado "mito das três raças", conceito especialmente identificado nas obras de Darcy Ribeiro, Roberto DaMatta e Gilberto Freyre, que trata da formação populacional brasileira de acordo com classificações raciais. Já com relação ao trabalho de Lévi-Strauss, o compositor menciona diretamente um dos livros mais conhecidos do antropólogo francês, denominado "Tristes trópicos". É possível verificar tais conexões no seguinte trecho destacado da canção "Retórica sentimental":

\section{Moro num lugar comum, junto daqui}

\section{Chamado Brasil}

Feito de três raças tristes, folhas verdes de tabaco e o guaraná guarani 
Alegria, namorados, alegria de Ceci (...)

E por falar no sabiá

O poeta Gonçalves Dias é que sabia

Sabe lá se não queria uma Europa bananeira

Diga lá, tristes trópicos

Sabiá, laranjeiras

A presença de intertextualidades também se demonstrava com relação a obras e menções feitas a outros ícones musicais, de ordem nacional e internacional. Em "Como se fosse pecado", do álbum Todos os sentidos - Belchior dialoga diretamente com Jorge Ben Jor, criador e grande expoente do ritmo hoje conhecido por "samba rock", ao aludir e unir os títulos das canções "Take it easymy brother Charles" e "Charles, anjo 45", lançadas pelo músico carioca em 1969 - esta última, posteriormente regravada por Caetano Veloso. É também nessa letra que Belchior faz o primeiro uso da tradução do título da música beatle "Happinessis a warmgun", quando emprega o verso "a felicidade é uma arma quente", que se repetirá na canção-homenagem ao vocalista do grupo britânico, John Lennon, em "Comentário a respeito de John", de Era uma vez um homem e seu tempo.

$\mathrm{O}$ recurso da intertextualidade retorna à obra de Belchior, agora em referência feita às artes plásticas, desta vezcom a deferência do artista nordestino ao trabalho de Alfredo Volpi na música "Ondas Tropicais", de Baihuno, quando as bandeirinhas de São João presentes em várias obras do artista plástico ítalo-brasileiro ganham destaque na menção feita pelo compositor. Essas mesmas bandeirinhas típicas do estilo de produção de Volpi colorem a capa deste disco de Belchior, conforme apontado por Josely Carlos (2007, p. 229), em ilustração produzida pelo próprio músico cearense. A tradição popular volta a ganhar destaque com Belchior em "Pequeno mapa do tempo", ao reproduzir "Medo, o meu boi morreu / O que será de mim? / Manda buscar outro, maninha, no Piauí", oriundo da tradicional cantiga "O meu boi morreu".

Até mesmo os ouvintes de Belchior recebem espaço significativo no sistema criativo do artista: em "Resposta à carta de fã", de Melodrama, Belchior cria uma interação com seu público, na forma de uma interlocução direta e manifestada de maneira fundamental na construção da letra, do título ao conteúdo, além da presença de uma tirada irônica com o Tropicalismo e Jorge Ben logo na sequência, acompanhado de um breve desabafo reflexivo sobre a relação da poesia com a modernidade, como se vê em trecho da canção destacado a seguir: 
Baby, respondo enfim aquela carta de fã que você mandou pra mim

Sabe, quase que eu ia fazendo a canção tropical que você me pediu

Mas quem sou eu, mentalidade mediana, para imitar Jorge Ben? (...)

Poema, o que é um poema? Isto não é do meu tempo

Tempo de sex, drugand rock androll, computador

Sobre os constantes diálogos traçados por Belchior com obras de outros músicos, JoselyCarlos (2007, p. 49) considera que "quando um sujeito investe interdiscursivamente, por meio da intertextualidade (...) ou metadiscursividade, ele está construindo/delimitando a sua própria identidade num espaço discursivo permeado por diversos posicionamentos".

Em certa medida, Belchior se alimenta e reinterpreta o estilo trovador de Bob Dylan, assim como de seu constante diálogo entre música, poesia e literatura, embora já tenha alegado que somente conheceu o trabalho de Dylan após suas produções iniciais. Nesse sentido, cabe ressaltar a convergência de influências entre ambos os músicos, especialmente a preferência pelos escritores e poetas da "geração beatnik" norte-americana, notadamente Allen Ginsberg e Jack Kerouac, eventualmente citados por Belchior em entrevistas.

O autor de "Como Nossos Pais", entretanto, admitiu e justificou uma certa "economia" nas melodias de suas músicas como uma influência direta do canto gregoriano, priorizando a formulação de letras extensas. Já o aspecto literário das composições de Belchior sempre foi associado ao trabalho de Bob Dylan, que, por sua vez, foi agraciado em 2016 com o Prêmio Nobel de Literatura daquele ano, sendo um caso com maior peso exemplificativo da capacidade de expansão literária e poética tendo a música como ponto de difusão primordial.

Em mais uma referência a Bob Dylan, o cantor inicia a letra de "Onde jazz meu coração", do disco Cenas do próximo capítulo com "Ei, senhor meu rei do tamborim", em tradução livre nordestina de "Mr. Tambourine Man", um dos maiores sucessos de Dylan, onde Belchior pede ao seu interlocutor, "rei do ganzá", que "cante um cantar, forme um repente pra mim".

Dessa forma, por mais que, ao menos num primeiro momento, não houvesse uma ligação direta entre eles, a similaridade entre os trabalhos e a inevitável comparação se justifica pelas fontes de inspiração artística em comum. Essa similaridade é verificável na canção "Antes do fim”, breve faixa que encerra o álbum Alucinação, desenvolvendo-se com o uso de gaita e violão folk e reproduzindo o estilo Dylan de fazer música. 


\section{Conclusão}

Expandindo a análise para além do aspecto literário, temos na obra de Belchior um conjunto de composições que dialoga de distintas maneiras com tópicos do pensamento social brasileiro, mostrando-se também de grande importância para a compreensão de temas sociais e políticos do país.

O compositor de canções do quilate de Paralelas, Velha Roupa Colorida e Apenas um Rapaz Latino-Americano gravou e foi regravado por muitos de seus pares, obtendo grande sucesso comercial e de crítica, com uma legião de fãs que se renova até os dias atuais, cinco décadas após o início de sua atividade como músico, dada a sensibilidade, a habilidade diante da complexidade temática e o caráter de diálogo com o popular que havia em seu trabalho.

Belchior passeou seus versos pelos mais diversos temas do noticiário e do imaginário social contemporâneos ao seu trabalho: as letras abordavam reflexões e opiniões sobre temas tão distintos quanto preconceito geográfico - especialmente contra nordestinos, relações amorosas, política, poesia, fluxos migratórios, artes em geral e (a falta de) liberdade de expressão durante a ditadura então vigente no país. Trata-se de uma carreira que demonstra ser de grande valor para estudos e pesquisas sobre a história da música brasileira, a partir de sua condição de artista bem-sucedido e consagrado como um verdadeiro ícone da música cearense.

\section{Referências}

BELCHIOR, Antonio Carlos. Alucinação. Polygram/Philips, 1976.

. Baihuno. MoviePlay, 1993.

.Cenas do próximo capítulo. Paraíso/Odeon, 1984.

Coração Selvagem. Warner, 1977.

Eldorado. MoviePlay, 1993.

. Elogio da loucura. Polygram, 1988.

Era uma vez um homem e o seu tempo. Warner, 1979.

. Melodrama. Polygram, 1987.

Revista Crioula - $\mathbf{n}^{\circ} \mathbf{2 6}$ - Relações entre literatura e música na produção de língua portuguesa

$2^{\circ}$ Semestre 2020 
. Mote e glosa. Chantecler, 1974.

. Objeto Direto. Warner, 1980.

. Todos os Sentidos. Warner, 1978.

CARLOS, Josely Teixeira. Muito além de "apenas um rapaz latino-americano vindo do interior": investimentos interdiscursivos das canções de Belchior. 2007. 277f. - Dissertação (Mestrado) - Universidade Federal do Ceará, Departamento de Letras Vernáculas, Programa de Pós-graduação em Linguística, Fortaleza (CE), 2007. Disponível em: $<$ http://www.repositorio.ufc.br/bitstream/riufc/8767/1/2007_dis_jtcarlos.pdf > . Acesso em: 12 set. 2020.

COSTA, Nelson Barros da. Cordas vocais de aço - a música cearense da década de 70. IN: Anais da Jornada do Grupo de Estudos Linguísticos do Nordeste, Natal, 04 - 07 de set 2012. Anais... Natal: EDUFRN, 2012. Disponível em: <http:// www.repositorio.ufc.br/bitstream/riufc/31818/1/2012_eve_nbcosta.pdf>. Acesso em: 23 out. 2020.

OLIVEIRA, Antonia; SOUSA, Maria; LEITE, Francisco. Marcas intertextuais na canção Velha roupa colorida, de Belchior. Revista do Programa de Pós-graduação em Letras da Universidade de Passo Fundo, vol 13, n 3, Passo Fundo, 2017. Disponível em: <http://seer.upf.br/index.php/rd/article/view/7272>. Acesso em: 25 set 2020.

RIBAS, Helena Macedo. Entre vícios e virtudes: a sátira dos goliardos medievais (séculos XI - XIII). Revista Cadernos de Clio, vol. 5. Curitiba, 2014. Disponível em: < https://revistas.ufpr.br/clio/article/view/40222>. Acesso em: 18 out. 2020.

SILVA, Gislene. Era uma vez um homem e o seu tempo: aspectos éticos e estéticos na lírica de Belchior.Revista Estudos de Literatura Brasileira Contemporânea. Brasília, 2006. Disponível em http://periodicos.unb.br/index.php/estudos/ article/view/2115/1680. Acesso em: 17 set. 2020. 